\title{
PELATIHAN MUSIKALISASI GURINDAM SEBAGAI UPAYA PENDIDIKAN KARAKTER BAGI SISWA SMA
}

\author{
Maya Aprilia ${ }^{1}$, Suparman $^{2}$, Evi Eliana $^{3}$, Khairunnissa $^{4}$, Sugiarti $^{5}$ \\ ${ }^{1}$ Universitas PGRI Palembang \\ korespondensi email: mayaaprilia499@gmail.com \\ ${ }^{2}$ Universitas PGRI Palembang \\ email: parmansu901@gmail.com \\ ${ }^{3}$ Universitas PGRI Palembang \\ email: evielianards@gmail.com \\ ${ }^{4}$ Universitas PGRI Palembang \\ email: nisssa1999j3@gmail.com \\ ${ }^{5}$ Universitas PGRI Palembang \\ email: sugiartialtiq@gmail.com
}

\begin{abstract}
The Student Creativity Program in the field of community service aims to provide character education to students and preserve Indonesian literary culture through musical training in Gurindam. This activity was carried out for five months in Assanadiyah High School Palembang led by Mr. Kasbun Dahir, S.Pd, M.Sc. The number of partner members in this activity is 10 people, namely class XI IPA. The method used in this activity consists of; preparation and counseling, assignments and training, presentations and performances, and evaluation. The results obtained are $92 \%$ of students aware of the importance of loving the local culture and $86 \%$ of students are able to compose gurindam and the formation of gurindam literary studio named Sanggurdiyah. Thus this activity provides a major influence on the importance of loving the local culture.
\end{abstract}

Keywords: character education; musicals; literature; gurindam.

\begin{abstract}
ABSTRAK
Program Kreativitas Mahasiswa bidang pengabdian kepada masyarakat ini bertujuan untuk memberikan pendidikan karakter kepada peserta didik dan melestarikan budaya sastra indonesia melalui pelatihan musikalisasi Gurindam. Kegiatan ini dilaksanakan selama lima bulan di SMA Assanadiyah Palembang yang di pimpin oleh Bapak Kasbun Dahir, S.Pd, M.Si. Jumlah anggota mitra dalam kegiatan ini sebanyak 10 orang yaitu kelas XI IPA. Metode yang dilakukan pada kegiatan ini terdiri dari; persiapan dan penyuluhan, pemberian tugas dan berlatih, persentasi dan pementasan, dan evaluasi. Hasil yang diperoleh yaitu $92 \%$ peserta didik menyadari akan pentingnya mencintai budaya daerah dan $86 \%$ peserta didik mampu mengarang gurindam serta terbentuknya Sanggar sastra gurindam yang diberi nama Sanggurdiyah. Dengan Demikian kegiatan ini memberikan pengaruh besar akan pentingnya mencintai budaya daerah.
\end{abstract}

Kata Kunci: pendidikan karakter; musikalisasi; sastra; gurindam. 


\section{PENDAHULUAN}

Plaju adalah sebuah kecamatan yang terletak di kota Palembang Sumatera Selatan. Dari data sekolah yang ada di Kecamatan Plaju hanya satu sekolah yang akan menjadi mitra kami pada PKM Pengabdian Kepada Masyarakat (PKMM) yaitu SMA Assanadiyah Palembang yang dipimpin oleh bapak Kasbun Dahir, S.Pd, M.Si. SMA ini terletak di JIn.KH Balqi No.137, RT 06/05, 16 Ulu, Kec.Sebrang Ulu II, kota Palembang, Sumatera Selatan 30117. SMA Assanadiyah Palembang ini termasuk kategori sekolah yang berada pada tahap perkembangan karena sekolahnya baru terakreditasi "B" namun, jumlah peserta didik dan fasilitas sekolahnya masih kurang.

Seiring dengan perkembangan zaman dan kecanggihan teknologi saat ini dapat memberikan pengaruh besar terhadap perkembangan di Indonesia. Namun jika pengaruh tersebut tidak dimanfaatkan ke arah yang positif maka pengaruh budaya luar tesebut dapat merusak karakter peserta didik (Arifin \& Tamrin, 2019). Teknologi yang diciptakan lebih mengutamakan manfaat daripada nilai-nilai akibatnya manusia kehilangan akar tradisi bahkan jati dirinya sendiri, sehingga yang tertinggal hanyalah cerita (Kustyarini, 2014) (Ngafifi, 2014).

Berdasarkan pendapat tersebut terdapat dua pemasalahan yaitu kehilangan adat istiadat/tradisi yang sudah ada pada zaman nenek moyang dahulu dan kehilangan jati diri bangsa. Untuk itu, semua rakyat Indonesia memiliki tugas yang sama yaitu melestarikan budaya yang ada dan menanamkan pendidikan karakter kepada peserta didik (generasi Muda).

Pendidikan karakter peserta didik dapat diberikan di sekolah pada materi pembelajaran bahasa Indonesia yaitu Sastra Indonesia. Alasannya karena Sastra mempunyai peran yang sangat penting dalam pendidikan karakter sebab Sastra membahas berbagai nilai-nilai yang terkandung dalam hidup dan kehidupan manusia (Rahman, 2018). Selain itu, Sastra juga mengutamakan unsur keindahan kata sehingga pembaca dapat terhibur dan termotivasi untuk mempelajarinya. Karya sastra merupakan penyampaian bahasa baik secara lisan maupun tulisan yang disampaikan dari generasi ke generasi. Karya sastra lama umumnya berbentuk prosa seperti hikayat, dongeng, dan legenda sedangkan puisi berupa Gurindam, puisi, pantun, seloka, talibun, mantra dan syair (Supriyantini \& Arifin, 2019) (Sugiarti, 2016).

Berdasarkan beberapa jenis karya sastra lama tersebut yang perlu dilestarikan dan dapat menanamkan pendidikan karakter yaitu Gurindam XII karya Raja Ali Haji. Gurindam merupakan suatu kata yang berasal dari bahasa sansekerta yang merupakan suatu puisi melayu tradisional (Akmal, 2015) (Sirait, 2018). Gurindam XII memiliki keunikan tersendiri daripada jenis karya sastra lama lainnya, terkenal karena pesan-pesan yang terkandung di dalamnya meliputi: nasehat budi pekerti, agama, moral dan tingkah laku selain itu, karena ketokohan pengarang yaitu Raja Ali Haji yang dilahirkan di Pulau Penyengat, Kepulauan Riau (Windiatmoko, 2016). Gurindam XII ini memiliki 12 pasal dan setiap pasal terdapat makna yang berbeda akan tetapi, 
Gurindam XII isinya sudah mencakup nasehat tentang hidup dan kehidupan manusia (Hidayah, 2015).

Pada Pasal $1 \& 2$ berisi nasehat tentang agama, Pasal 3 berisi tentang hati-hati dalam bertindak atau budi pekerti, Pasal 4 berisi nasehat tentang tabiat yang baik dengan menjaga dan mendidik hati dari sifat tercela, Pasal 5 berisi tentang pendidikan dengan memperluas pergaulan bersama orangorang yang baik, Pasal 6 berisi tentang pergaulan, baik dengan sahabat, guru, keluarga, dan kawan yang selalu mengarahkan kearah yang baik, Pasal 7 berisi nasehat kepada orang tua untuk menanamkan karakter yang baik kepada anaknya agar anak-anaknya tidak menyusahkan orangtua di kemudian hari, Pasal 8 berisi tentang nasehat agar tidak percaya pada orang yang selalu berprasangka buruk pada orang lain, Pasal 9 berisi tentang moral pergaulan antara pria dan wanita, Pasal 10 berisi tentang nasehat agar selalu menghormati orang tua, Pasal 11 berisi tentang nasehat agar seorang pemimpin harus amanah dalam menjalankan tugas dan selalu menjauhi sifat tercela, dan Pasal 12 berisi tentang nasehat agar manusia ingat kematian dan hari akhir.

Penjelasan mengenai isi dari Gurindam XII ini sangat tepat untuk menanamkan pendidikan karakter kepada peserta didik. Akan tetapi, di zaman modern ini Gurindam sudah tidak lestari lagi dikalangan pelajar maupun masyarakat. Kebanyakan peserta didik merasa malu dan gengsi untuk mempelajari gurindam. Dalam hal ini, agar budaya lama dapat terus dilestarikan dan budaya modern juga dapat diikuti maka terjadilah Akulturasi budaya. Akulturasi yaitu perpaduan budaya yang kemudian menghasilkan budaya baru tanpa menghilangkan unsur-unsur asli dalam budaya tersebut (Kodiran, 1998) (Mahmud, 2012).

Berdasarkan hasil pembicaraan dengan mitra ternyata permasalahan yang dihadapi yaitu sebagai berikut: 1) sekolah belum menemukan solusi mengenai cara mendidik karakter peserta didik untuk menanamkan rasa cinta budaya daerah dan budaya nasional di SMA Assanadiyah Palembang; 2) kurangnya kegiatan ekskul di sekolah; 3) peserta didik tidak mengetahui pentingnya melestarikan budaya daerah sendiri seperti budaya sastra tersebut; 4) peserta didik tidak mengetahui pengaruh negatif dari budayabudaya luar tersebut; dan 5) Peserta didik dan guru belum pernah menyajikan Akulturasi budaya sastra dalam bentuk musikalisasi Gurindam. Dari permasalahan mitra diatas maka permasalahan yang paling utama yaitu menyajikan Akulturasi budaya sastra dalam bentuk musikalisasi Gurindam. Program PKM-M ini bertujuan untuk membentuk suatu sanggar Musikalisasi Gurindam.

\section{METODE PELAKSANAAN}

Berdasarkan kesepakatan bersama antara mitra dan pengusul. Program ini akan dilaksanakan dalam bentuk pendampingan kepada peserta didik yang membentuk kelompok dengan jumlah anggota 10 orang. Sasaran 
dalam kegiatan ini adalah peserta didik kelas XI IPA di SMA Assanadiyah Palembang dengan harapan peserta didik tersebut dapat mengarang gurindam dan mampu mementaskan musikalisasi gurindam tersebut di lingkungan sekolahnya. Pelaksanaan kegiatan ini akan dilakukan dalam jangka waktu 5 bulan. Adapun metode yang akan dilakukan pada kegiatan ini adalah sebagai berikut:

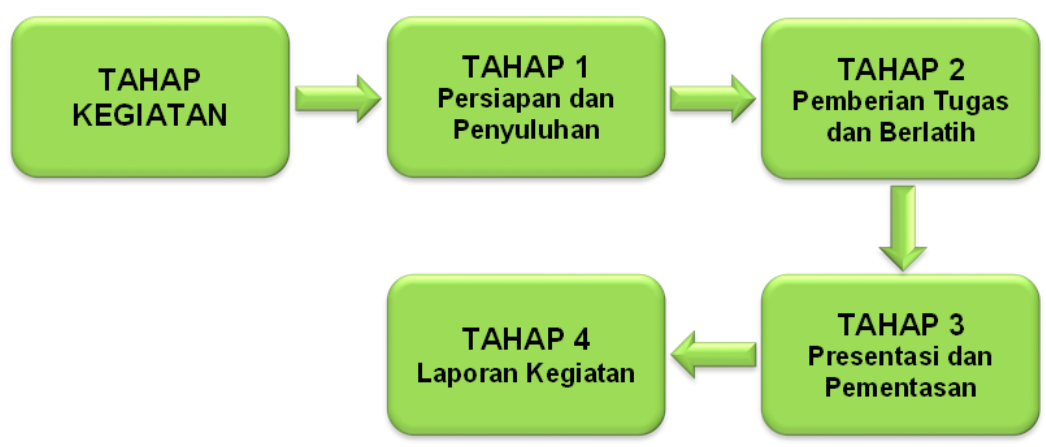

Gambar 1. Tahapan Kegiatan dimana:

Kegiatan ini dilakukan berdasarkan dengan tahapan-tahapan diatas

Tahap 1: Persiapan kegiatan dan Penyuluhan

Pada tahap ini tim pelaksana akan menginformasikan kepada mitra tentang prosedur kegiatan dan menyiapkan semua keperluan yang dibutuhkan dalam kegiatan ini baik materi maupun peserta didik. Kemudian, tim pelaksana melakukan penyuluhan tentang pentingnya mencintai budaya daerah sendiri dan pemberian materi dan angket mengenai Sastra gurindam.

Tahap 2: Pemberian Tugas, dan Berlatih

Pada tahap ini tim pelaksana akan mengarahkan dan membimbing peserta didik dalam proses pembuatan dan perlatihan gurindam.kemudian, peserta didik akan mempersentasikan hasil karya kelompok gurindam di depan kelas. Setelah itu, tim pelaksana mengarahkan peserta didik untuk menyiapkan semua keperluan untuk pementasan.

Tahap 3: Persentasi dan Pementasan

Pada tahap ini peserta didik akan melaksanakan kegiatan pementasan di lapangan sekolah tersebut. Kemudian, tim pelaksan membuat laporan hasil kegiatan tersebut. Berdasarkan metode diatas materi yang akan diberikan kepada peserta didik yaitu tentang seni Sastra lama mengenai Gurindam. Partisipasi dari mitra sangat mendukung kelancaran kegiatan ini. Dan diharapkan kegiatan ini dapat berlanjut untuk masa seterusnya.

Tahap 4: Laporan Kegiatan

Pada tahap ini tim pelaksana PKM akan membuat laporan hasil kegiatan berupa laporan kemajuan, laporan akhir, dan tercapainya luaranluaran. Berdasarkan metode diatas materi yang akan diberikan kepada peserta didik yaitu tentang seni sastra lama mengenai Gurindam. Adapun 
teknik pengumpulan data menggunakan angket atau kuisinoner tertutup dengan pilihan jawaban ya dan tidak.

\begin{tabular}{cc} 
Tabel 1. Skor Penilaian Angket \\
\hline \multicolumn{2}{c}{ Skor Penilaian } \\
\hline Ya & Tidak \\
1 & 0
\end{tabular}

\section{HASIL DAN PEMBAHASAN}

Kegiatan PKM-M ini dilaksanakan di SMA Assanadiyah Palembang selama 5 bulan yang diikuti oleh peserta didik kelas XI IPA I sebanyak 10 orang, terdiri dari 3 laki-laki dan 7 perempuan. Kegiatan ini diresmikan pada tanggal 20 April 2019 yang dihadiri oleh kepala SMA Assanadiyah Palembang dan dosen pembimbing PKM-M sekaligus penyuluhan mengenai pentingnya mencintai budaya daerah sendiri. Pada tahap penyuluhan peserta didik diberikan layanan mengenai pentingya melestarikan budaya sastra gurindam, pengenalan macam-macam budaya sastra yang ada di Indonesia, dampak negatif jika budaya sastra gurindam tidak dilestarikan di lingkungan pelajar maupun masyarakat umum dan informasi mengenai sikap pelajar dalam menyikapi perubahan teknologi, sosial dan budaya. Setelah pembukaan langkah selanjutnya pada kegiatan PKM-M ini yaitu pelatihan musikalisasi gurindam.

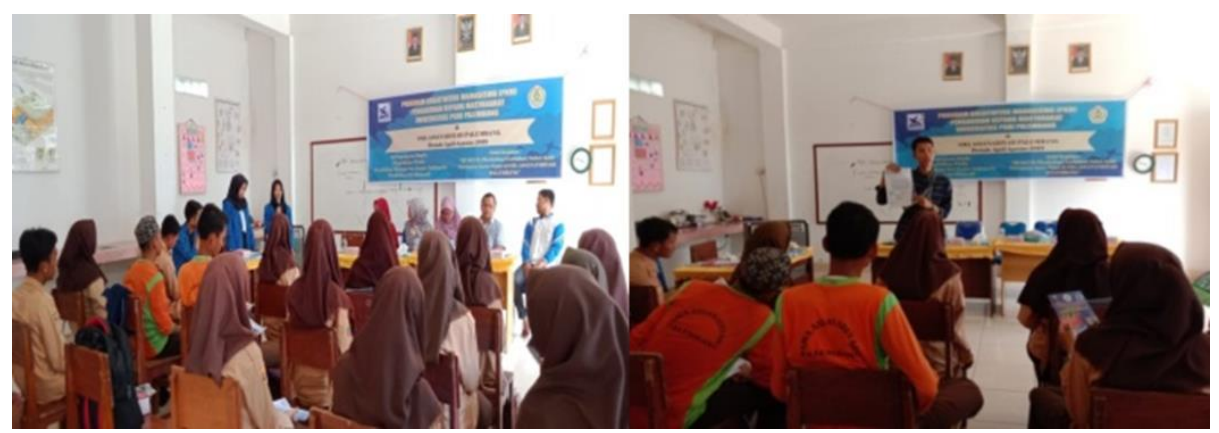

Gambar 2. kegiatan pelatihan musikalisasi gurindam dan pemberian tugas

Pelaksanaan kegiatan pelatihan musikalisasi gurindam dan pemberian tugas dimulai pada tanggal 25 April 2019. Peserta didik yang menjadi mitra pada kegiatan PKM-M ini diberikan arahan terlebih dahulu mengenai kegiatan pelatihan musikalisasi gurindam dan penjelasan materi gurindam yang disampaikan langsung oleh pelaksana PKM dari program studi Bahasa Indonesia. Adapun langkah-langkah pelaksanaan kegiatan ini yaitu menentukan ketua kelompok, menentukan pemain musik dan penyair. Peserta didik yang bertugas sebagai pemain musik yaitu Arya Sanjaya dan Miko Santoso sedangkan penyair bernama Sherly Alviana. Setelah itu, membuat 
kelompok kecil yang terdiri dari 5 orang, masing-masing kelompok diberikan tugas membuat karangan gurindam selama satu minggu. Berikut tabel hasil penilaian karangan gurindam yaitu:

Tabel 2. Hasil Penilaian Karangan Gurindam

\begin{tabular}{|c|c|c|c|c|}
\hline \multirow[b]{2}{*}{ Kelompok } & \multicolumn{3}{|c|}{ Jenis Penilain } & \multirow[b]{2}{*}{$=\frac{\text { jumlah total }}{3}$} \\
\hline & Kebahasaan & $\begin{array}{c}\text { Pemilihan } \\
\text { kata atau } \\
\text { diksi }\end{array}$ & $\begin{array}{l}\text { Kesesuain } \\
\text { dengan } \\
\text { ciri-ciri } \\
\text { gurindam }\end{array}$ & \\
\hline 1 & 88 & 83 & 88 & 86.34 \\
\hline \multirow[t]{2}{*}{2} & 86 & 80 & 88 & 84.67 \\
\hline & & & Rata-rata & $85.5=86 \%$ \\
\hline
\end{tabular}

Keterangan:

NA: Nilai Akhir

Pada minggu kedua peserta didik mulai melaksanakan latihan gurindam 12 karangan Raja Ali Haji. Isi gurindam yang akan ditampilkan yaitu sebanyak 12 pasal. Setiap pasal gurindam memiliki makna tertentu yang saling berkesinambungan. Pada pasal pertama dan kedua diiringi musik lagu "petang lah petang" lagu ini merupakan lagu daerah yang berasal dari kabupaten Lahat. Pada pasal ketiga penyampaian gurindam dilakukan oleh penyair sedangkan pada pasal keempat dan kelima diiringi musik lagu "ya saman" termasuk lagu daerah yang berasal dari Palembang. Kemudian, pada pasal ketujuh dan delapan menggunakan musik "ramadhan tiba" karya Opick lagu ini mencermikan bahwa SMA Assanadiyah ini termasuk sekolah yang mengedepankan nilai-nilai agama. Selanjutnya, pada pasal kesembilan isi gurindam disampaikan dalam bentuk puisi sedangkan pasal 10 dilsampaikan oleh penyair dengan diiringi drama mengenai makna dari isi gurindam kesepuluh tersebut. Terakhir pada pasal sebelas dan duabelas gurindam disampaikan melalui iringan musik "cindai" lagu ini mencerminkan bahwa gurindam berasal dari bahasa Melayu. Dengan perbedaan musik dan cara penyampaian gurindam di atas dimaksudkan agar penyampain gurindam lebih menarik. Selain dari musik dan cara penyampaian, tata panggung dan keindahan busana juga mendukung keberhasilan pementasan.

Berdasarkan hasil tahap pelatihan dapat dikategorikan bahwa peserta didik mampu mengikuti penyampaian gurindam dengan cara diiringi musik modern daripada disampaikan melalui syair lama. Hal ini dapat dilihat dari tabel hasil angket berikut: 
Tabel 3. Tabel Hasil Angket Respon Mitra

\begin{tabular}{cc}
\hline Nama Siswa & Frekuensi \\
\hline Siswa 1 & 15 \\
Siswa 2 & 15 \\
Siswa 3 & 13 \\
Siswa 4 & 14 \\
Siswa 5 & 13 \\
Siswa 6 & 14 \\
Siswa 7 & 13 \\
Siswa 8 & 14 \\
Siswa 9 & 14 \\
Siswa 10 & 14 \\
Rata -rata & $\mathbf{9 2 \%}$ \\
\hline
\end{tabular}

\section{Angket Respon Mitra terhadap Motivasi Belajar} Gurindam

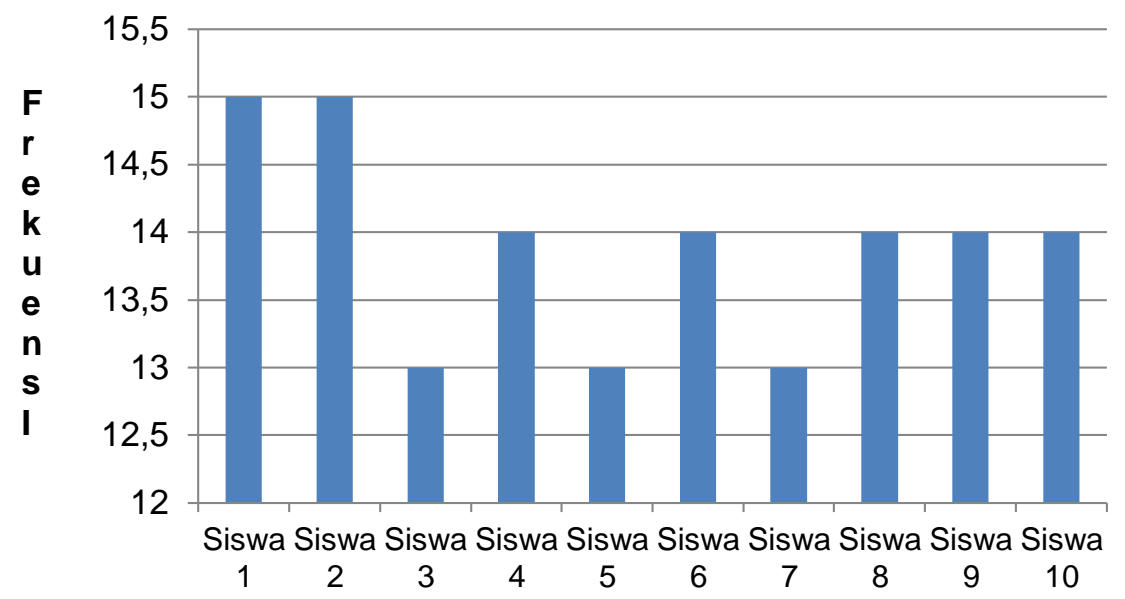

Gambar 3. Diagram hasil angket respon mitra

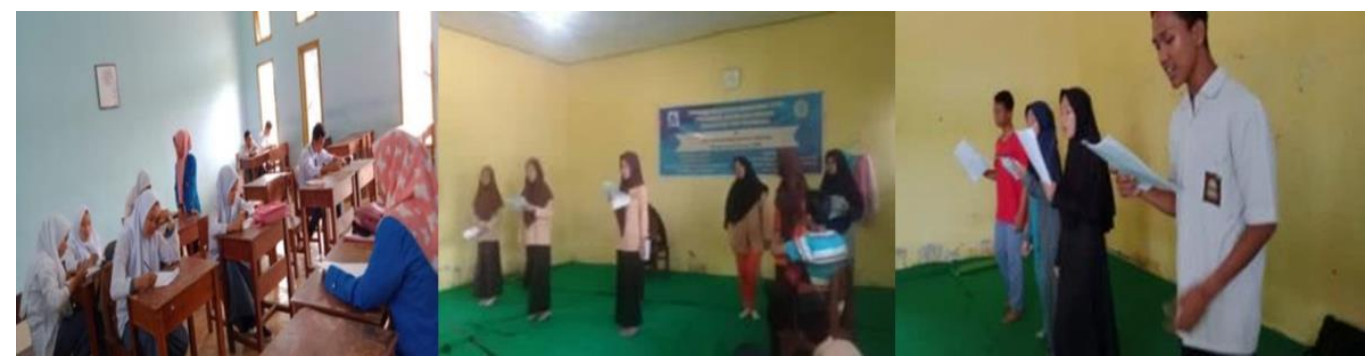

Gambar 4. Membagikan angket dan presentasi perkelompok 
Selanjutnya pelaksanaan pementasan musikalisasi gurindam di laksanakan pada tanggal 20 juni 2019 dimulai pukul 08.30 wib yang hadiri oleh dosen pembimbing Sugiarti, M.Pd dan Kepala SMA Assanadiyah Palembang sekaligus pengukuhan Sanggar Sastra Gurindam di SMA Assanadiyah Palembang. Sanggar ini dinamakan SANGGURDIYAH yaitu Sanggar Gurindam Assanadiyah yang diketuai oleh Arya Sanjaya dengan guru Pembimbing Sari Wulandari, S.Pd.

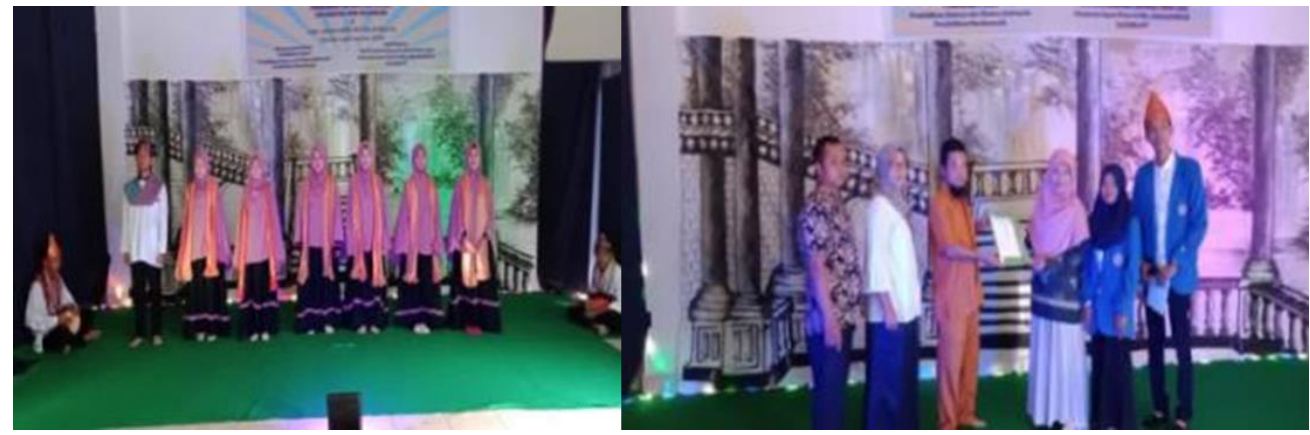

Gambar 5. Pelaksanaan pementasan dan pengukuhan kepengurusan sanggar

\section{KESIMPULAN}

Berdasarkan hasil dan pembahasan di atas dapat disimpulan bahwa PKM ini memberikan pengaruh yang baik kepada peserta didik di SMA Assanadiyah Palembang dilihat dari hasil angket sikap dan peran aktif peserta didik pada pelaksanaan PKM ini yaitu sebanyak $92 \%$ dari jumlah seluruh peserta didik yang memiliki pengetahuan dan termotivasi mempelajari budaya sastra Gurindam, dan sebesar $86 \%$ peserta didik mampu mengarang gurindam. Kemudian, serta 10 orang peserta didik mampu melaksanakan pementasan gurindam dengan baik dan mampu menjalankan kepengurusan sanggar sastra gurindam yang telah disahkan oleh Kepala sekolah. Setelah dilakukan kegiatan PKM ini diharapkan peserta didik dan guru dapat menjalankan kepengurusan sanggar sastra sebagai kegiatan ekstrakulikuler di sekolah dan guru dapat lebih mengembangkan lagi ide kegiatan-kegiatan yang lebih kreatif dan menarik.

\section{UCAPAN TERIMA KASIH}

Ucapan terima kasih kepada Dosen pembimbing Sugiarti, M.Pd dan Direktorat Riset dan Pengabdian kepada masyarakat (DRPM), Direktorat Jenderal dan penguatan dan Riset dan Pengembangan: Kementrian riset dan, Teknologi dan Pendidikan tinggi (KEMERISTEKDIKTI), yang telah membiayai kegiatan PKM ini sesuai dengan kontrak pengabdian kepada masyarakat nomor:193/E.36/LPPKMK/UPGRI/2019 serta semua pihak yang membantu kegiatan PKM ini. 


\section{DAFTAR RUJUKAN}

Akmal. (2015). Kebudayaan Melayu Riau (Pantun, Syair, Gurindam). Jurnal Risalah, 26(4), 159-165. https://doi.org/10.24014/jdr.v26i4.1283

Arifin, Z., \& Tamrin, T. (2019). Peningkatan Kompetensi Microcontroller Siswa SMK. Jurnal Inovasi Hasil Pengabdian Masyarakat (JIPEMAS), 2(1), 49-53. https://doi.org/10.33474/jipemas.v2i1.1772

Hidayah, L. N. (2015). Gurindam 12 Karya Raja Ali Haji (Studi Analisis Pasal 1 - Pasal 12 Gurindam 12 Dengan Paradigma Pendidikan Islam) [Universitas Islam Negeri Maulana Malik Ibrahim Malang]. http://etheses.uin-malang.ac.id/5072/1/11110034.pdf

Kodiran. (1998). Akulturasi sebagai Mekanisme Perubahan Kebudayaan. Humaniora, 1(8). https://doi.org/10.22146/jh.v0i8.2064

Kustyarini. (2014). Sastra dan Budaya. LIKHITAPRAJNA. Jurnal IImiah.Fakultas Keguruan Dan IImu Pendidikan, 16(2), 1-13. http://likhitapradnya.wisnuwardhana.ac.id/index.php/likhitapradnya/artic le/view/34

Mahmud, A. (2012). Akulturasi Kebudayaan Timur Tengah Ke Indonesia. Wahana Akademika: Jurnal Studi Islam Dan Sosial, 14(2), 17-28. https://doi.org/10.21580/wa.v14i2.549

Ngafifi, M. (2014). Kemajuan Teknologi Dan Pola Hidup Manusia Dalam Perspektif Sosial Budaya. Jurnal Pembangunan Pendidikan: Fondasi Dan Aplikasi, 2(1), 33-47. https://doi.org/10.21831/jppfa.v2i1.2616

Rahman, A. (2018). Peran Pembelajaran Bahasa dan Sastra Indonesia Dalam Pembentukan Karakter Peserta Didik. Edukasi Kultura : Jurnal Bahasa, Sastra Dan Budaya, 1(1). https://doi.org/10.24114/kultura.v1i1.11732

Sirait, L. (2018). Revitalisasi Gurindam Dua Belas Karya Raja Ali Haji Sebagai Pendidikan Berbasis Kearifan Lokal Etnis Melayu. Sosietas, 8(1), 446451. https://doi.org/10.17509/sosietas.v8i1.12497

Sugiarti. (2016). Estetika dalam Novel Jatisaba Karya Ramayda Akmal. Litera: Jurnal Penelitian Bahasa, Sastra Dan Pengajarannya, 15(1), 100-110. https://doi.org/10.21831/ltr.v15i1.9769

Supriyantini, \& Arifin, E. Z. (2019). Nilai Pendidikan Dan Moral Dalam Novel "Dendam" Si Yatim-Piatu Karya Sintha Rosse. Journal of Chemical Information and Modeling, 5(1), 47-75. http://journal.unas.ac.id/pujangga/article/view/731

Windiatmoko, D. U. (2016). Analisis Wacana Dalam Gurindam XII dan Nilai Pendidikan Karakter Serta Implikasinya Sebagai Materi Ajar Sastra. KEMBARA: Jurnal Keilmuan Bahasa, Sastra, Dan Pengajarannya, 1(3), 12-22. https://doi.org/10.22219/kembara.v2i1.4016 